\title{
ОСОБЕННОСТИ ТЕЧЕНИЯ АУТОИММУННОГО ПОЛИГЛАНДУЛЯРНОГО СИНДРОМА 2 ТИПА (КЛИНИЧЕСКИЙ СЛУЧАЙ)
}

\author{
Каширина Е.Ж., Дангыт Д.М., Рыженкова Е.М., Брызгалина С.М., Королева Ю.Б. \\ НГИУВ - филиал НГИУВ ДПО РМАНПО МЗРФ, Новокузнецк \\ ГАУЗ «НГКБ №1», Новокузнецк
}

В настоящее время в практике врача эндокринолога все чаще встречаются аутоиммунные полигландулярные синдромы (АПС). По современной классификации существует четыре типа АПС. Распространенность АПС 2 типа в популяции составляет 1,4-4,5 на 100 тыс. населения, отмечается рост заболеваемости. Приводим собственный случай наблюдения не типичного течения АПС 2 типа. Пациентка, М., 49 лет госпитализирована в эндокринологическое отделение ГАУЗ «НГКБ№1» в экстренном порядке с жалобами на резкую слабость, сухость во рту, тошноту, постоянную рвоту после попытки принятия пищи на протяжении двух недель. Из анамнеза известно, что сахарный диабет 1 типа диагностирован в 2003 году (стаж 17 лет). С дебюта заболевания на базис-болюсной инсулинотерапии. В 2018 году перенесла гипогликемическую кому. В ноябре 2019 года находилась на стационарном лечении по месту жительства в связи с развитием диабетического кетоацидоза (ДКА) средней степени тяжести. На фоне проводимой терапии состояние пациентки улучшилось, но целевые показатели гликемии не достигнуты, выписана с явлениями кетоза. Через две недели с явлениями тяжелого ДКА госпитализирована в ГАУЗ «НГКБ№1», где проводилась регидратационная терапия, инсулинотерапия, антибактериальная по общепринятым стандартам. Однако, на протяжении трех суток на фоне лечения, пациентка отказывалась от еды, сохранялась тошнота и рвота. Объективный статус: рост - 156 см, вес -50 кг., ИМТ - 20,5, кожа сухая, цвета загара, явления витилиго на кистях рук, резкий запах ацетона. АД 90/70 мм рт.ст., пульс - 120 в минуту, ритмичный. Живот мягкий, безболезненный. Дыхание везикулярное, хрипов нет. Щитовидная железа не увеличена, плотноватая, без узлов. Данные лабораторного обследования: гемоглобин - 98 г/л, эритроциты $-3,69 \times 10^{12} / л$, лейкоциты $-12,1 \times 10^{9} / л$, лимфоциты - 54,4\%, СОЭ - 35 мм/ч. Кетоновые тела мочи - ++++, суточная протеинурия - 0,678 г/л, калий - 6,3 ммоль/л, натрий - 128 ммоль/л, мочевина - 5,2 ммоль/л, креатинин - 101 мкмоль/л. Гликемический профиль при поступлении: 26,1-15,0-14,0-12,8 ммоль/л. В связи с сохраняющимся кетоацидозом, рвотой, гипотонией на фоне проводимой регидратационной терапии, гиперкалиемией и гипонатриемией, в сочетании с темным цветом кожи, витилиго, анемией, назначено дообследование для исключения АПС. Кортизол резко снижен - 5,88 нмоль/л, ТТГ повышен - 9,1 мкMЕ/мл, Т4 св. 12,4 пмоль/л, АТ к ТПО - 150,2 MЕ/мл. УЗИ щитовидной железы: V - 6,6 см³, признаки аутоиммунного тиреоидита. Установлен диагноз: Аутоиммунный полигландулярный синдром 2 типа (сахарный диабет 1 типа, первичная надпочечниковая недостаточность, первичный гипотиреоз, витилиго, анемия). В лечении добавлены глюкокортикоиды и минералокортикоиды, тиреогормоны. На фоне проведенного лечения достигнуты целевые показатели гликемии, купирован кетоацидоз, состояние пациентки стабилизировалось (прекратилась рвота, прибавила в весе, АД 120/80 мм рт.ст.). Таким образом, данный клинический случай показывает возможность не классического варианта развития АПС 2 типа (дебют заболевания с СД 1 типа, с последующим развитием надпочечниковой недостаточности и гипотиреоза спустя длительный период времени) и требует настороженности врачей в отношении своевременной диагностики АПС. 